\title{
EFECTO DEL GLUCORAFANO AISLADO DE FLORETES DE BRÓCOLI SOBRE LA GERMINACIÓN DE ESPORAS DE Colletotrichum gloeosporioides
}

\section{EFFECT OF THE GLUCORAFANO ISOLATED FROM BROCCOLI FLORETS ON THE GERMINATION OF Colletotrichum gloeosporioides SPORES}

\author{
Francisco M. Lara-Viveros ${ }^{1}$, Daniel Nieto-Angel ${ }^{2 \star}$, Cristian Nava-Díaz ${ }^{2}$, Gabriel Gutiérrez-Alonso ${ }^{3}$, \\ Óscar J. Ayala-Garay ${ }^{1}$ L. Alfonso Aguilar-Pérez ${ }^{2}$ y Teresa Martínez-Damián ${ }^{4}$
}

\begin{abstract}
${ }^{1}$ Postgrado de Recursos Genéticos y Productividad-Fisiología Vegetal, ${ }^{2}$ Postgrado de Fitosanidad-Fitopatología, Colegio de Postgraduados. Km 36.5 Carr. MéxicoTexcoco. 56230, Montecillo, Edo. de México. ${ }^{3}$ Divina Pastora 11. 76099, Col. Plazas del Sol 1a Seccion. Querétaro, Qro. ${ }^{4}$ Departamento de Fitotecnia, Universidad Autónoma Chapingo. Km 38.5 Carr. México-Texcoco. 56230, Chapingo, Edo. de México.

*Autor para correspondencia(dnieto@colpos.mx)
\end{abstract}

\section{RESUMEN}

La antracnosis provocada por Colletotrichum gloeosporioides es la enfermedad poscosecha más importante en las áreas productoras de mango (Mangifera indica L.) en todo el mundo, y la estrategia más empleada para controlarla es el tratamiento en precosecha y poscosecha con fungicidas sintéticos. Sin embargo, su uso está cada vez más restringido debido a que en los frutos se acumulan residuos potencialmente peligrosos para los consumidores. Los glucosinolatos son productos naturales que contienen nitrógeno y azufre, $\mathrm{y}$ se encuentran principalmente en plantas del orden de los Caparales y su actividad antimicrobiana se ha comprobado in vivo e in vitro. En este trabajo se colectaron frutos de mango con síntomas de antracnosis, y a partir de éstos se aisló e identificó el hongo Colletotrichum gloeosporioides. Las esporas del patógeno fueron colocadas en medio de cultivo PDA, adicionado con diferentes concentraciones de glucorafano $\left(1.54,0.92,0.46,0.15,0.02\right.$ y $\left.0 \mu \mathrm{g} \mu \mathrm{L}^{-1}\right)$, este último aislado de floretes de brócoli (Brassica oleracea cv. 'Itálica'). Se evaluó la germinación de las esporas hasta que el testigo alcanzó el máximo porcentaje de germinación. Las concentraciones de 1.54 y $0.92 \mu \mathrm{g} \mu \mathrm{L}^{-1}$ inhibieron en su totalidad la germinación de esporas después de $10 \mathrm{~h}$ de exposición. La concentración letal media $\left(\mathrm{CL}_{50}\right)$ fue de $0.65 \mu \mathrm{g} \mu \mathrm{L}^{-1}$. Con base en los resultados se plantea que el glucorafano representa una alternativa más sana para el consumidor, por ser capaz de controlar la antracnosis.

Palabras clave: Colletotrichum, glucorafano, poscosecha, germinación, mango.

\section{SUMMARY}

Anthracnose caused by Colletotrichum gloeosporioides, is the most important postharvest disease in mango (Mangifera indica $\mathrm{L}$.) producing areas worldwide, and the strategy most used to control this disease is the pre-and post-harvest treatment with fungicides, but their use is increasingly restricted due to public awareness of hazardous residues in the fruits. Glucosinolates are natural products containing nitrogen and sulfur, mainly found in plants from the order Caparales, and their antimicrobial activity has been shown elsewhere. For this work we collected mango fruits with anthracnose symptoms, and from them the fungus Colletotrichum gloeosporioides was isolated and identified. Pathogen spores were placed on PDA containing different concentrations of glucoraphane (1.54, 0.92, 0.46, 0.15, 0.02 y $\left.0 \mu \mathrm{g} \mu \mathrm{L}^{-1}\right)$ previously isolated from broccoli (Brassica oleracea $\mathrm{cv}$. 'Itálica') florets.
We evaluated spore germination until control treatment showed its highest percentage of germination. After $10 \mathrm{~h}$ of evaluation the concentrations of 1.54 and $0.92 \mu \mathrm{g} \mu \mathrm{L}^{-1}$, caused complete inhibition of spore germination. The median lethal concentration was $0.65 \mu \mathrm{g} \mu \mathrm{L}^{-1}$. Based on these results glucoraphane represents a friendly alternative for consumers, because of its capability to control anthracnose in harvested mango fruits.

Index words: Colletotrichum, glucoraphane, postharvest, germination, mango.

\section{INTRODUCCIÓN}

Los hongos patógenos de los frutos en poscosecha causan considerables pérdidas en la producción (Tripathi y Dubey, 2004), lo que se debe en gran medida a que los frutos tienen un gran contenido de nutrientes esenciales y mantienen un $\mathrm{pH}$ que favorece el crecimiento de dichos organismos (Moss, 2002). La antracnosis provocada por Colletotrichum gloeosporioides, es la enfermedad poscosecha más importante en las áreas productoras de mango (Mangifera indica L.) en todo el mundo (Dodd y Jeffries, 1997). Este hongo se caracteriza por permanecer en estado quiescente en frutos inmaduros e inducir importantes daños en poscosecha. Actualmente la estrategia más empleada para el control de la enfermedad, es el tratamiento en precosecha y poscosecha con fungicidas sintéticos; sin embargo su uso está cada vez más restringido debido a que en los frutos se acumulan residuos potencialmente peligrosos para los consumidores (Yonas y Amare, 2008).

Una de las sustancias más utilizadas en el control de esta enfermedad es el fungicida benomilo que somete al patógeno a una alta presión de selección, que junto con la alternancia de generaciones (reproducción sexual-asexual), facilita la aparición de cepas resistentes a esta molécula durante el ciclo de vida del hongo (Punnawich-Yenjita, 2010). La aparición de cepas resistentes hace necesario que se aplique mayor cantidad de fungicida y con mayor frecuencia; 
debido a esto existe una alta probabilidad de que los seres humanos estén expuestos a estos compuestos químicos y a los riesgos implícitos (Tripathi y Dubey, 2004). Por lo anterior, es necesario contar con alternativas inocuas al control químico que puedan incluirse en un manejo integrado de Colletotrichum gloeosporioides.

En años recientes ha habido un creciente interés en encontrar productos alternativos que permitan suplir a los fungicidas químicos, y se requiere que estos nuevos productos sean seguros para el ambiente y con un riesgo mínimo para la salud del ser humano (Martínez-Romero et al., 2008). Entre las estrategias que más se utilizan está el uso de compuestos naturales obtenidos de plantas, como jasmonatos, aceites esenciales o glucosinolatos (Tripathi y Dubey, 2004). Estos últimos contienen nitrógeno y azufre y se encuentran principalmente en las plantas del orden de los Caparales, orden que comprende plantas importantes desde el punto de vista agrícola; tal es el caso de las brassicaceas, como el brócoli (Brassica oleracea cv. 'Itálica') (Wittstock y Halkier, 2002).

Actualmente se conocen cerca de 120 glucosinolatos diferentes, cuya estructura básica incluye una cadena de carbono de tamaño variable derivada de aminoácidos. De acuerdo con el tamaño de esta cadena, los glucosinolatos se dividen en alifáticos, indólicos y aromáticos. En brócoli el glucosinolato presente en mayor concentración es el glucorafano, un glucosinolato alifático (Van-Eylen et al., 2009). Una vez que este compuesto es hidrolizado forma un isotiocinato llamado glucorafanina que ha mostrado un efecto en contra de patógenos que portan los alimentos (Brandi et al., 2006). Este compuesto ha sido probado en contra de patógenos de plantas como Monilinia laxa y Penicillium expansum en pera (Pyrus communis) (Mari et al., 1996; Mari et al., 2002), y en ambos trabajos los resultados en el control de estos patógenos fue bueno. Dado que los resultados con el glucarafano han sido alentadores en la inhibición de los patógenos arriba descritos y a que se requiere encontrar alternativas que sean más amigables con el ambiente e igualmente eficientes en el control de hongos patógenos, el objetivo del presente trabajo fue evaluar el efecto del glucorafano sobre la germinación de esporas de Colletotrichum gloeosporioides aislado de frutos de mango en poscosecha.

\section{MATERIALES Y MÉTODOS}

\section{Aislamiento y pruebas de patogenicidad}

Colletotrichum gloeosporioides se aisló a partir de frutos maduros de mango cv. 'Manila' con síntomas de antracnosis que fueron colectados en el Estado de Guerrero, México. Del tejido con síntomas se tomaron dos secciones de $0.5 \mathrm{~cm}$ en la parte terminal de la lesión del pericarpio, los cuales fueron desinfestados por inmersión en una solución de hipoclorito de sodio a $2 \%$ durante $2 \mathrm{~min}$, los tejidos se enjuagaron dos veces con agua destilada estéril. Cada tejido se sembró en el medio de cultivo denominado Papa Dextrosa Agar (PDA). Después de 7 d se observó el desarrollo de micelio el cual a los $10 \mathrm{~d}$ produjo conidios. A partir de un solo conidio se estableció un cultivo monospórico en medio Agua Agar (AA) y se incrementó en PDA.

La identidad del cultivo monospórico se estableció a nivel de especie por medio de claves morfológicas (Sutton, 1980; Bailey y Jerger, 1992). La patogenicidad del hongo se comprobó inoculando frutos de mango cv. 'Manila' en etapa de madurez de consumo. Antes de ser inoculados, los frutos se desinfectaron por inmersión en una solución de hipoclorito de sodio a $2 \%$ durante 5 min y se enjuagaron dos veces con agua destilada estéril. El pericarpio de los frutos (cáscara) fue herido con un palillo estéril, dicha herida alcanzó una profundidad de $3 \mathrm{~mm}$. Las heridas de los frutos fueron inoculadas con $20 \mu \mathrm{L}$ de una suspensión conidial que contenía 1 x $10^{-6}$ conidios $/ \mathrm{mL}$, que fue preparada a partir del cultivo monospórico de C. gloesporioides de 6 d de edad. El número de conidios en la solución se ajustó mediante un hematocitómetro. Al testigo no inoculado se le adicionó agua destilada estéril sobre las heridas. Los frutos inoculados se mantuvieron en cámara húmeda a $24 \pm 2$ ${ }^{\circ} \mathrm{C}$ durante $10 \mathrm{~d}$. Al concluir el periodo de incubación, los frutos se analizaron visualmente para determinar el desarrollo de síntomas de antracnosis. A partir de las heridas que desarrollaron síntomas se re-aisló el hongo y se identificó mediante claves morfológicas (Sutton, 1980; Bailey y Jerger, 1992).

\section{Aislamiento de glucorafano}

\section{Material vegetal}

Se utilizaron floretes de brócoli cosechados durante enero del 2008, en la ciudad de Celaya en Guanajuato, México. Los floretes se transportaron en hielo a una temperatura aproximada de $4{ }^{\circ} \mathrm{C}$, hasta el laboratorio en donde fueron procesados inmediatamente después de su llegada.

\section{Procesamiento del material vegetal}

Los floretes de brócoli $(\approx 200 \mathrm{~g})$ se maceraron en una mezcla de metanol y agua (80:20, v/v), en cantidad suficiente para cubrir la muestra. Después de $48 \mathrm{~h}$ el macerado se filtró en papel filtro de poro medio, y los sólidos retenidos en el filtro se re-extrajeron de la mezcla de metanol y agua; el filtrado se conservó en un recipiente ámbar. El proceso de extracción/re-extracción se repitió en tres ocasiones. Los extractos filtrados fueron concentrados en un rotavapor con presión reducida a $60{ }^{\circ} \mathrm{C}$. 


\section{Separación y aislamiento del glucorafano}

La separación del glucorafano a partir del extracto crudo de brócoli se realizó mediante cromatografía en capa fina cuya fase móvil consistió en una mezcla de propanol, etanol, ácido acético y agua (30:10:10:10; v/v/v/v), al igual que lo hicieron Wagner et al. (2009). Las placas utilizadas fueron de sílica gel 60 F256 con indicador de fluorescencia $\left(\right.$ Merck $\left.{ }^{\circledR}\right)$, recortadas a 100 x $100 \mathrm{~mm}$. En cada extremo de la placa se colocaron $2 \mu \mathrm{L}$ de un estándar comercial de glucorafano (SIGMA ${ }^{\circledR}$ ) a una concentración de $5 \mu \mathrm{g} \mu \mathrm{L}^{-1}$, y en el espacio entre ambos extremos se colocó extracto crudo de brócoli obtenido mediante el procedimiento antes descrito. Una vez que la cromatografía se desarrolló, se calculó la posición del estándar en la placa por medio del coeficiente de retención $\left(R_{f}\right)$ con la fórmula: $R_{f}=Z(x) / Z(f) \times(100)$, donde; $Z(x)=$ distancia del punto de aplicación a la molécula, y $Z(f)=$ distancia del punto de aplicación al frente del disolvente. El valor del $R_{f}$ para el estándar comercial del glucorafano fue de 60 y toda la fracción de sílica que tuvo este mismo valor de coeficiente de retención se colectó y se resuspendió en metanol, para después ser centrifugado por 15 min a $5000 \mathrm{x} g$. El sobrenadante se colectó y se colocó en un vaso de precipitado por 10 min y luego en una placa de calentamiento a $50{ }^{\circ} \mathrm{C}$. Además se hizo pasar gas nitrógeno por el vaso de precipitado con la finalidad de concentrar la muestra. Una vez concentrada, la muestra se resuspendió en $1 \mathrm{~mL}$ de metanol grado HPLC.

\section{Método para determinar la concentración del glucorafano aislado}

En una placa de cromatografía de 50 x $50 \mathrm{~mm}$ se colocaron diferentes volúmenes $(2,4,6$ y $8 \mu \mathrm{L})$ del estándar de glucorafano (SIGMA $\left.{ }^{\circledR}\right)$. Una vez que la cromatografía se desarrolló, se determinó el factor de retención $\left(R_{f}\right)$ del estándar, y por medio de un densitómetro Desaga modelo CD-60® se obtuvieron los valores de altura y área bajo la curva que generó la molécula de glucorafano, para luego determinar la longitud de onda a la cual el compuesto presenta una máxima absorción. La placa se analizó a longitudes de onda entre 220 y $280 \mathrm{~nm}$. A partir de los datos de altura y área bajo la curva generados de concentraciones conocidas del estándar de glucorafano se ajustó un modelo de regresión por medio del programa estadístico SAS v.9 para Windows, que resulto en una ecuación lineal del tipo $y=m x+b$; por interpolación se determinó la concentración del glucorafano aislado del extracto crudo de brócoli. El experimento de calibración se hizo por triplicado en tres experimentos independientes.

\section{Evaluación del efecto del glucorafano sobre la germinación de esporas de Colletotrichum gloeosporioides}

\section{Bioensayos}

En recipientes translúcidos con una capacidad de $300 \mu \mathrm{L}$ se colocaron $150 \mu \mathrm{L}$ de medio de cultivo PDA. Previo a la solidificación del medio de cultivo, éste se mezcló con 50 $\mu \mathrm{L}$ de glucorafano aislado de brócoli y diluido en metanol analítico, de tal manera que se alcanzaran las concentraciones utilizadas en los bioensayos (Cuadro 1). Los recipientes que contenían cada una de las diferentes concentraciones de glucorafano fueron adicionados con una solución de esporas de C. Gloeosporioides, a una concentración de $1 \times 10^{6}$ esporas/mL. Los recipientes se colocaron en cámara húmeda donde fueron incubados por 5,7 y $10 \mathrm{~h}$ a $28 \pm 3{ }^{\circ} \mathrm{C}$. De cada concentración de glucorafano se midieron tres repeticiones independientes.

\section{Variables y análisis estadísticos}

Los porcentajes de germinación obtenidos fueron sometidos a pruebas de normalidad y de homostacidad por medio del programa estadístico SAS v.9 para Windows. Una vez que se verificó que los datos tuvieron un comportamiento normal, se hicieron análisis de varianza y pruebas

Cuadro 1. Concentraciones de glucorafano utilizadas para determinar el efecto de esta molécula sobre la germinación de esporas de Colletotrichum gloeosporioides.

Tratamiento Cantidad de Cantidad de glucorafano Concentración final de Concentración final de glucorafano en un metanol $(\mu \mathrm{L}) \quad$ aislado de brócoli $(\mu \mathrm{L})$ glucorafano en un volumen volumen de $150 \mu \mathrm{L}$ de PDA $+50 \mu \mathrm{L}$ de la de $50 \mu \mathrm{L}(\mu \mathrm{g} / \mu \mathrm{L}) \quad$ solución de glucorafano $(\mu \mathrm{g} / \mu \mathrm{L})$

\begin{tabular}{lllll}
\hline 1 & 0 & 50 & 6.15 & 1.54 \\
2 & 20 & 30 & 3.69 & 0.92 \\
3 & 35 & 15 & 1.84 & 0.46 \\
4 & 45 & 5 & 0.61 & 0.15 \\
5 & 49.5 & 0.5 & 0.06 & 0.02 \\
6 & 50 & 0 & 0 & 0 \\
\hline
\end{tabular}


múltiples de medias de Tukey $(\alpha=0.05)$. El área bajo la curva que generó la germinación de las esporas fue calculada para cada una de las repeticiones por el método de los trapezoides (Liengme, 2002), con cuyos datos se calculó la efectividad del glucorafano por medio de la fórmula $y=\left(t_{t}-\right.$ $\left.t_{x} / t_{t}\right)(100)$; donde $y=$ efectividad expresada en porcentaje, $t_{t}=$ área bajo la curva promedio del tratamiento testigo, $\mathrm{y}$ $t_{x}=$ área bajo la curva del tratamiento a evaluar. Además se ajustaron modelos de regresión lineal, y se utilizó el comando Solver de Microsoft Excel 2007® para determinar la efectividad letal media $\left(\mathrm{CL}_{50}\right)$ y la efectividad letal $\left(\mathrm{CL}_{100}\right)$.

\section{RESULTADOS Y DISCUSIÓN}

\section{Concentración del glucorafano aislado}

Las placas de cromatografía en las que se corrieron diferentes concentraciones del estándar glucorafano y desarrolladas en el sistema de solventes arriba descrito, mostraron que la longitud de onda a la cual la molécula de glucorafano absorbe una mayor cantidad de luz es de $224 \mathrm{~nm}$ (Figura 1). Longitudes de onda similares han sido utilizadas por otros autores; por ejemplo, Cheng-Guo et al. (2009) utilizaron 226 y $280 \mathrm{~nm}$ para detectar la presencia de glucosinolatos en floretes de brócoli sometidos a atmósferas modificadas. Por su parte, Brown et al. (2003) utilizaron una longitud de $229 \mathrm{~nm}$ y glucosinolatos aislados de Arabidopsis thaliana para determinar la germinación de estas semillas.

Las ecuaciones de regresión generadas a partir de las lecturas a $224 \mathrm{~nm}$ mostraron significancia estadística $(\mathrm{P}=$ $0.007)$ y un coeficiente de determinación de 0.92 . La ecuación generada fue: $y=6.1436383+\left(1.119 \times 10^{-15}\right)(a \times h)^{3}$; donde $y=$ concentración de glucorafano en $\mu \mathrm{g} \mu \mathrm{L}^{-1}, a=$ área bajo la curva de la molécula de glucorafano, y $h=$ altura del pico de la molécula de glucorafano obtenidos por densitometría. El $R_{f}$ de la fracción que correspondió con la migración del estándar fue de 60. Por otra parte, la ecuación permitió determinar que el glucorafano aislado del extracto crudo de brócoli fue de $6.15 \mu \mathrm{g} \mu \mathrm{L}^{-1}$, con una pureza de $91.36 \%$.

\section{Bioensayos}

La prueba de comparación de medias mostró diferencias significativas en el porcentaje de germinación de las esporas en función de las concentraciones de glucorafano ensayadas a las $10 \mathrm{~h}$ (Cuadro 2). El porcentaje de germinación más alto en el testigo (más de $80 \%$ ) se presentó $10 \mathrm{~h}$ después de que las esporas se colocaron en los recipientes con PDA; este porcentaje de germinación para esporas de C. gloeosporioides es similar al encontrado por GutiérrezAlonso et al. (2001) quienes reportaron valores que oscilan de 81.9 a $83.2 \%$. En las concentraciones de 1.54 y $0.92 \mu \mathrm{g}$ $\mu \mathrm{L}^{-1}$ se observó una germinación de 0 y $8 \%$ respectivamente, mientras que en el tratamiento testigo se observó una germinación superior a $80 \%$. El efecto de los glucosinolatos en contra de algunos patógenos fue observado por Lazzeri et al. (1993), quienes encontraron actividad de algunos de estos compuestos en contra de nematodos del género

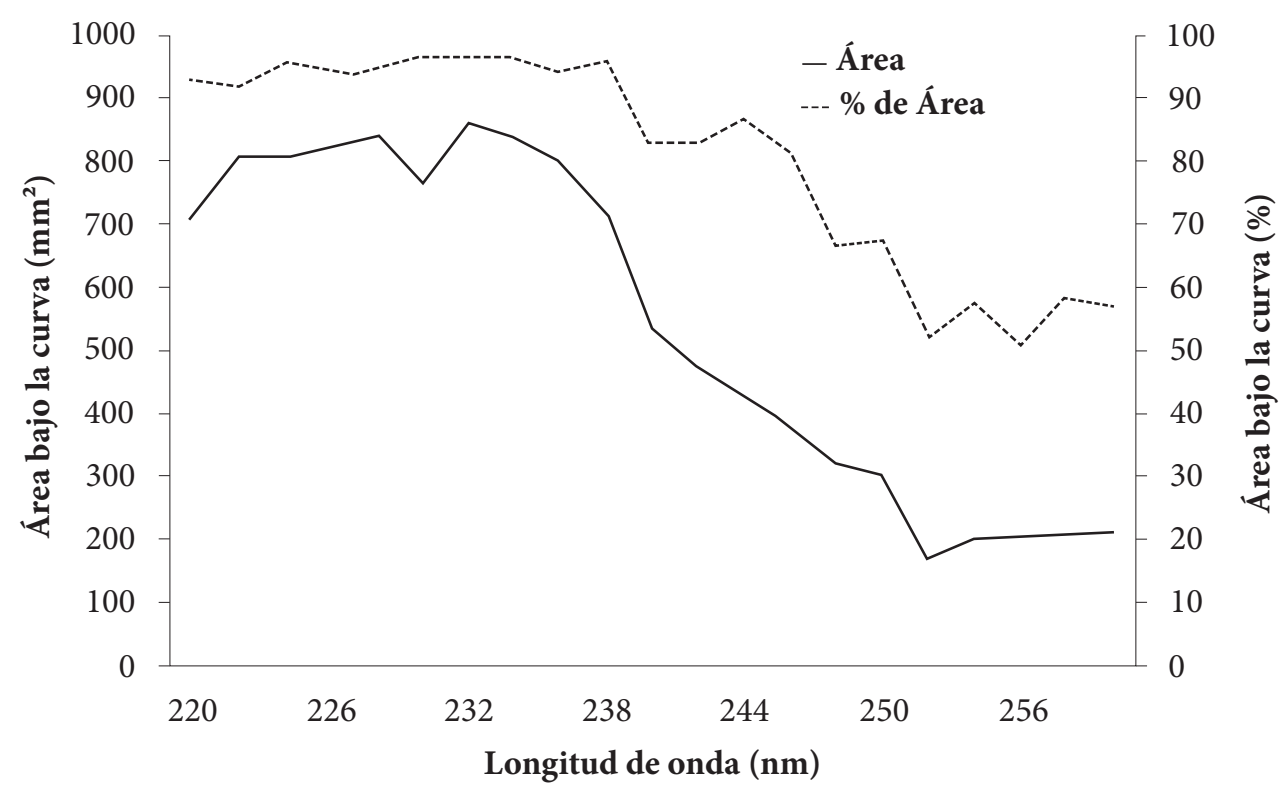

Figura 1. Comportamiento de un estándar de glucorafano en cromatografía en capa fina acoplada a densitometría. 
Heterodera, mientras que Manici et al. (1997) encontraron que algunos glucosinolatos tienen actividad en contra de hongos fitopatógenos.

Los resultados de este trabajo muestran que las esporas de C. gloeosporioides tienen una respuesta diferencial al glucorafano a lo largo del tiempo de evaluación, y que las concentraciones más altas resultan en un menor porcentaje de germinación (Figura 3). Por otro lado, la ecuación de regresión lineal permitió estimar el porcentaje de efectividad del glucorafano en contra de las esporas de Colletotrichum gloeosporioides, con significancia estadística y coeficiente de determinación alto $\left(\mathrm{P}=0.001\right.$ y $\left.\mathrm{R}^{2}=0.99\right)$. La ecuación utilizada fue $Y=-8.07085022 \mathrm{Con}+119.648813 \mathrm{Con}^{2}$ -13.259505 $\mathrm{Con}^{3}+5.52744929$; donde $Y=$ efectividad en porcentaje, y Con $=$ concentración de glucorafano aislado de brócoli en $\mu \mathrm{g} \mu \mathrm{L}^{-1}$.

La ecuación mostró que la efectividad media $\left(\mathrm{CL}_{50}\right)$ fue de $0.65 \mu \mathrm{g} \mu \mathrm{L}^{-1}$, mientras que la concentración que mostró una efectividad de $100 \%\left(\mathrm{CL}_{100}\right)$ fue de $0.97 \mu \mathrm{g} \mu \mathrm{L}^{-1}$ (Figura 4). El efecto inhibitorio sobre la germinación de esporas de hongos fitopatógenos también ha sido observado en otros glucosinolatos; por ejemplo, Maria et al. (2008) encontraron un efecto inhibitorio de $50 \%$ en la germinación de esporas de M. laxa, cuando éstas fueron sometidas a vapores de diferentes isotiocinatos en concentraciones de 0.04 hasta $0.27 \mathrm{mg} \mathrm{L}^{-1}$.

Debido a la actividad antifúngica del glucorafano, éste podría ser utilizado como un tratamiento poscosecha para disminuir la incidencia de antracnosis provocada por

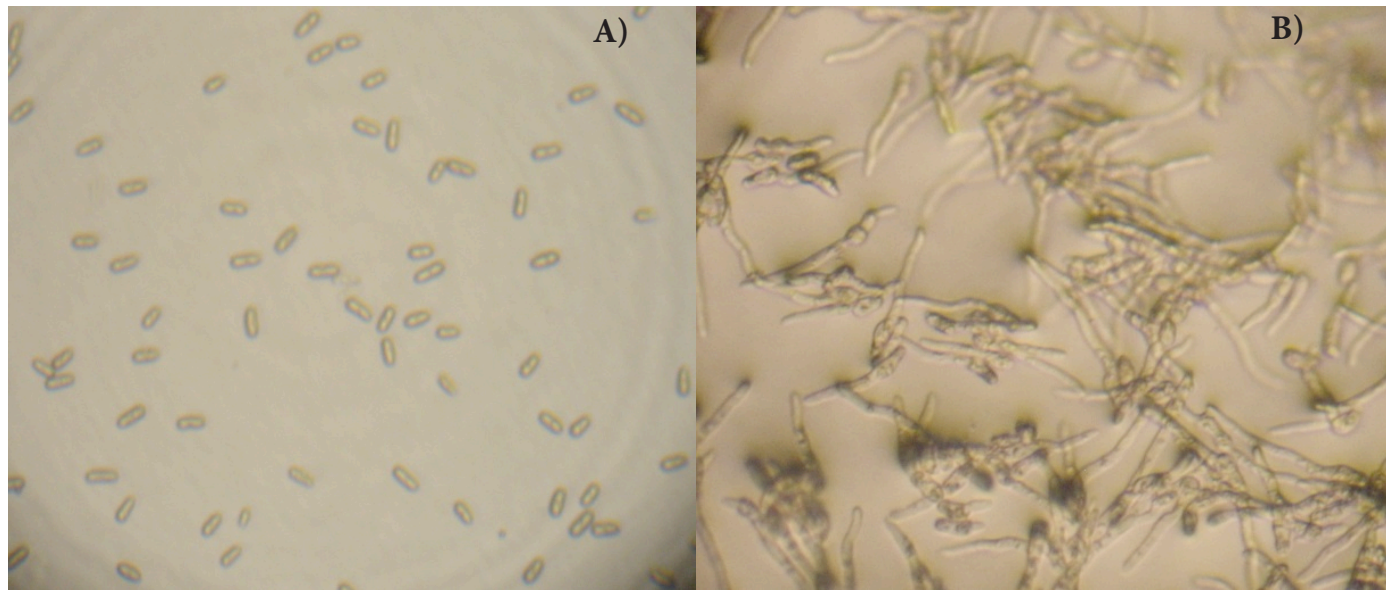

Figura 2. Efecto de diferentes concentraciones de glucorafano aislado de brócoli sobre la germinación de esporas de Colletotrichum gloeosporioides aislados de frutos de mango. A) cultivadas durante $10 \mathrm{~h}$ en el medio PDA, a una concentración de glucorafano de $1.54 \mu \mathrm{g} \mu \mathrm{L}^{-1}$. B) Esporas de Colletotrichum gloeosporioides cultivadas durante $10 \mathrm{~h}$ en el medio PDA sin adición (testigo negativo).

Cuadro 2. Germinación de esporas de Colletotrichum gloeosporioides en diferentes concentraciones de glucorafano aislado de brócoli.

\begin{tabular}{lccc}
\hline Dosis $(\mu \mathrm{g} / \mu \mathrm{L})$ & Germinación $^{\dagger}(\%) 5 \mathrm{~h}$ & Germinación $^{\dagger}(\%) 7 \mathrm{~h}$ & Germinación $^{\dagger}(\%) 10 \mathrm{~h}$ \\
\hline 1.54 & $0.0 \mathrm{a}$ & $0 \mathrm{a}$ & $0.0 \mathrm{~b}$ \\
0.92 & $0.0 \mathrm{a}$ & $2.5 \mathrm{a}$ & $8.0 \mathrm{~b}$ \\
0.46 & $1.5 \mathrm{a}$ & $4.5 \mathrm{a}$ & $60.0 \mathrm{a}$ \\
0.15 & $2.0 \mathrm{a}$ & $9.5 \mathrm{a}$ & $82.5 \mathrm{a}$ \\
0.02 & $1.5 \mathrm{a}$ & $11.0 \mathrm{a}$ & $77.0 \mathrm{a}$ \\
0 & $2.5 \mathrm{a}$ & $11.0 \mathrm{a}$ & $85.5 \mathrm{a}$ \\
Probabilidad & 0.14 & 0.08 & 0.0001 \\
$\mathrm{R}^{2}$ & 0.67 & 0.74 & 0.98
\end{tabular}

${ }^{\dagger}$ Letras iguales en una columna indican ausencia de diferencias significativas (Tukey, 0.05). 


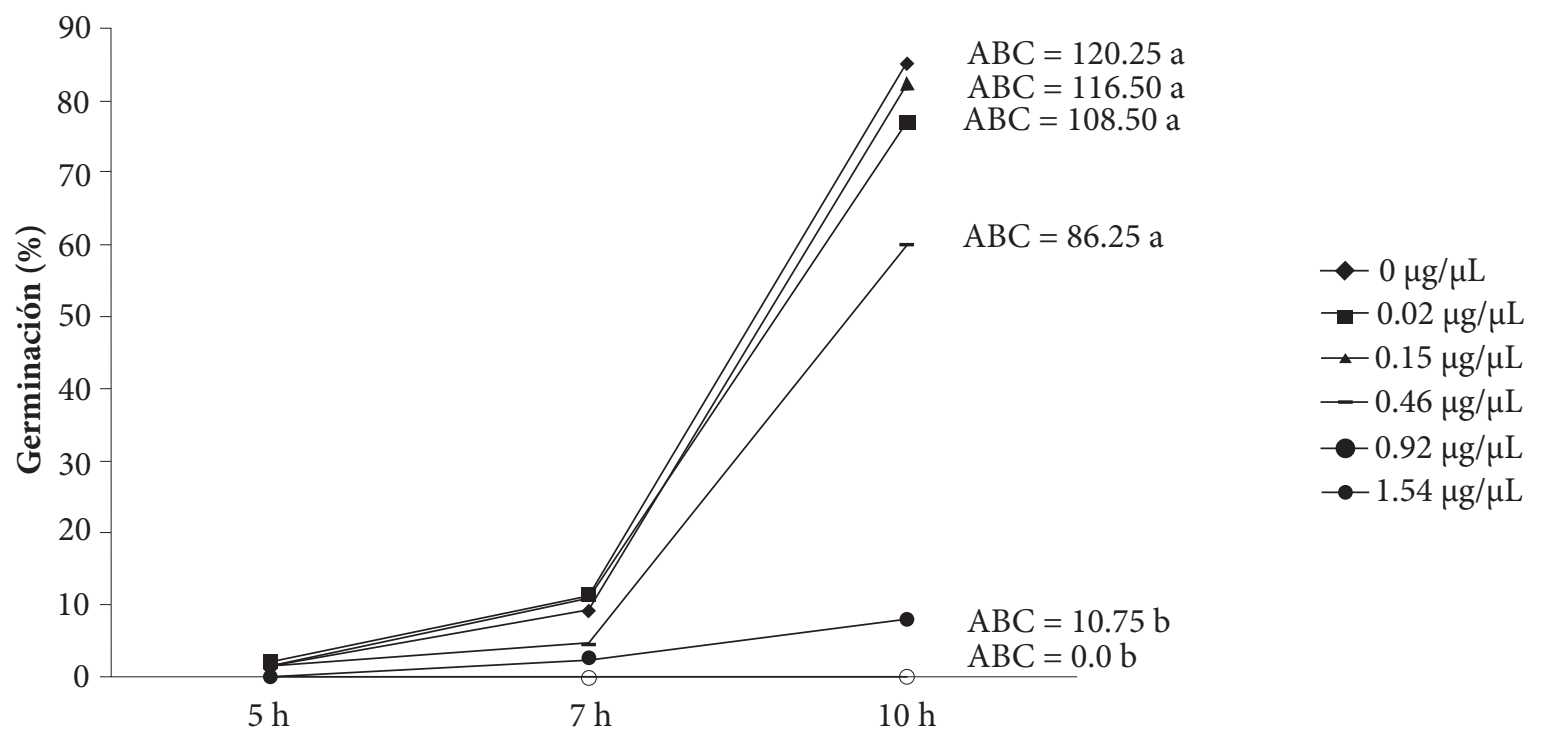

Figura 3. Curvas de germinación de esporas de Colletotrichum gloeosporioides a través del tiempo. $\mathrm{ABC}=$ área bajo la curva de germinación de esporas.

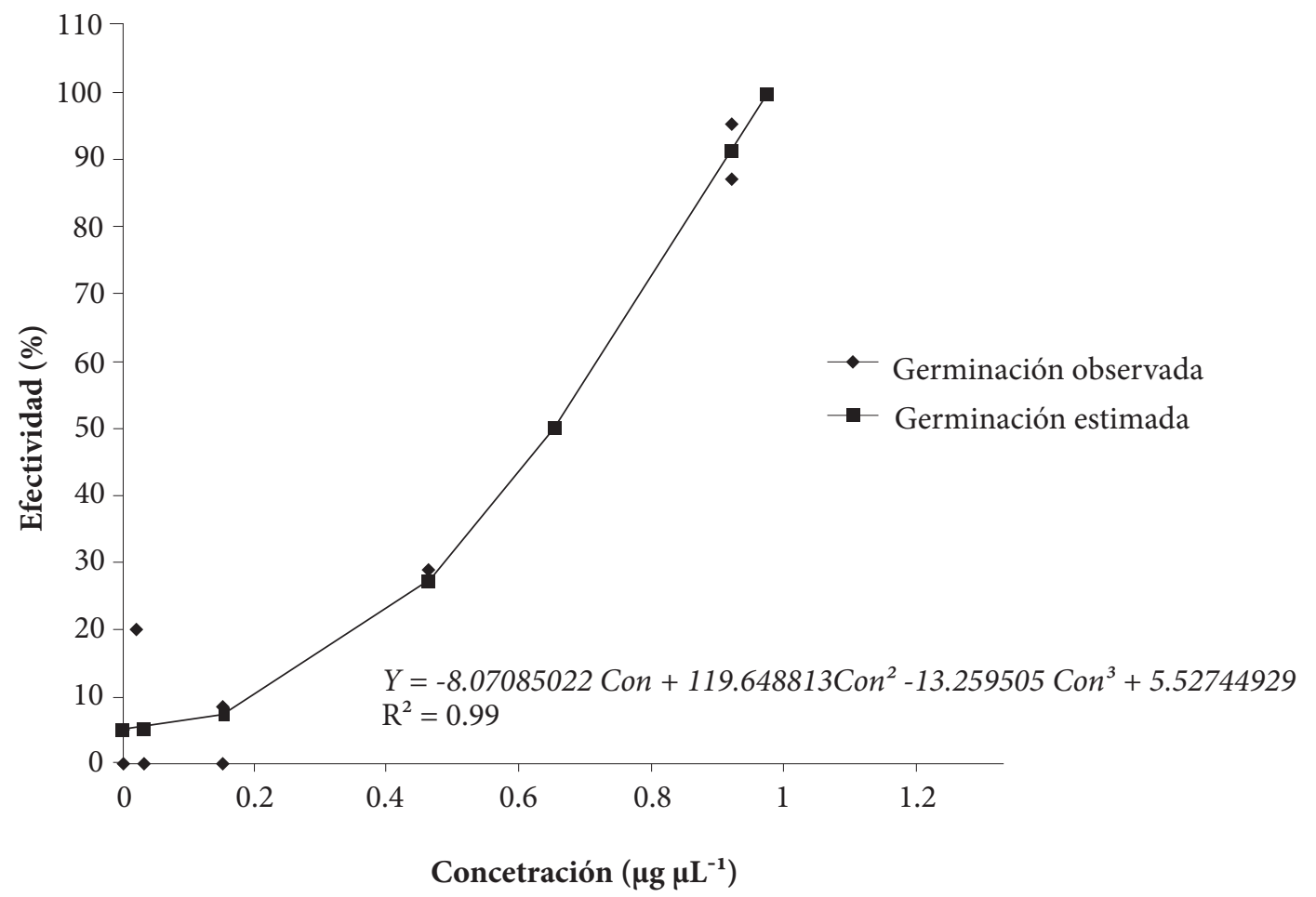

Figura 4. Modelo de regresión para estimar la efectividad biológica de glucorafano en contra de la germinación de esporas de Colletotrichum gloeosporioides. Con = concentración de glucorafano en el medio de cultivo. 
Colletotrichum gloeosporioides en frutos de mango después de haber sido cosechados.

\section{Conclusiones}

El glucorafano aislado del brócoli mostró efecto inhibitorio sobre la germinación de esporas de Colletotrichum gloeosporioides. La concentración letal media fue de $0.65 \mu \mathrm{g}$ $\mu \mathrm{L}^{-1}$, mientras que la $\mathrm{CL}_{100}$ fue de $0.97 \mu \mathrm{g} \mu \mathrm{L}^{-1}$. El conocimiento del efecto de metabolitos secundarios de plantas sobre las esporas de los hongos podría contribuir a encontrar nuevas alternativas en el manejo de Colletotrichum gloeosporioides en frutos de mango cosechados.

\section{BIBLIOGRAFÍA}

Bailey J. A. and M. J. Jerger (1992) Colletotrichum; Biology, Pathology and Control. C.A.B. International. United Kingdom. 338 p.

Brandi G., G. Amagliani, G. F. Schiavano, M. De-Santi and M. Sisti (2006) Activity of Brassica oleracea leaf juice on foodborne pathogenic bacteria. Journal of Food Protection 69:2274-2279.

Brown P. D., J. G. Tokuhisa, M. Reichelt and J. Gershenzon (2003) Variation of glucosinolate accumulation among different organs and developmental stages of Arabidopsis thaliana. Phytochemistry 62:471-481.

Cheng-Guo J., X. Chao-Jiong, W. Jia, Y. Jing, Y. Gao-Feng, W. BingLiang and W. Qiao-Mei (2009) Effect of modified atmosphere packaging on visual quality and glucosinolates. Food Chemistry 114:28-37.

Dodd J. C. and P. Jeffries (1997) Fruit diseases. In: The Mango: Botany, Production and Uses. R. E. Litz (ed). CAB International. United Kingdom. pp:257-280.

Gutiérrez-Alonso J. G., D. Nieto-Ángel, D. Téliz-Ortiz, E. ZavaletaMejía, H. Vaquera-Huerta, T. Martínez-Damían, F. Delgadillo-Sánchez (2001) Características de crecimiento, germinación, esporulación y patogenicidad de aislamientos de Colletotrichum gloeosporioides Penz. obtenidos de frutos de mango (Mangifera indica L). Revista Mexicana de Fitopatología 19:90-93.

Lazzeri L., R. Tacconi and S. Palmieri (1993) In vitro activity of some glucosinolates and their reaction products toward a population of the nematode Heterodera schachtii. Journal Agriculture and Food Chemistry 41:825-829.

Liengme B. V. (2002) A Guide to Microsoft Excel for Scientists and Engineers. (2 ed.). Butterworth-Heinemann. Oxfordshire, England. $271 \mathrm{p}$.

Manici M., L. Lazzeri and S. Palmieri (1997) In vitro fungitoxic activity of some glucosinolates and their enzyme-derived products toward plant pathogenic fungi. Journal Agriculture and Food Chemistry 45:2768-2773.

Mari M., O. Leoni, R. Lori and T. Cembal (2002) Antifungal vapourphase activity of allyl isothiocyanate against Penicillium expansum on pears. Plant Pathology 51:231-236.

Mari M., O. Leoni, R. Lori and A. Marchi (1996) Bioassay of glucosinolate derived isothiocyanates against post harvest pear pathogens. Plant Pathology 45:753-760.

Maria M., O. Leoni, R. Bernardi, F. Neri and S. Palmieri (2008) Control of brown rot on stonefruit by synthetic and glucosinolatederived isothiocyanates. Postharvest Biology and Technology 47:61-67.

Martínez-Romero D., M. Serrano, G. Bailén, F. Guillén, P. J. Zapata, J. M. Valverde, S. Castillo, M. Fuentes and D. Valero (2008) The use of a natural fungicide as an alternative to preharvest synthetic fungicide treatments to control lettuce deterioration during postharvest storage. Postharvest Biology and Technology 47:54-60.

Moss M. O. (2002) Mycotoxin review 1. Aspergillus and Penicillium. Mycologist 16:116-119.

Punnawich-Yenjita M. I. (2010) Fungicidal activity of compounds extracted from the pericarp of Areca catechu. Postharvest Biology and Technology 55:129-132.

Sutton B. C. (1980) The Coelomycetes: Fungi Iimperfecti with Picnidia, Acervuli and Stromata. Commonwealth Mycological Institute. United Kindom. 696 p.

Tripathi P. and N. K. Dubey (2004) Exploitation of natural products as an alternative strategy to control postharvest fungal rotting of fruit and vegetables. Postharvest Biology and Technology 32:235-245.

Van-Eylen D., N. Bellostas, B. W. Strobel, I. Oey, M. Hendrickx and A. Van-Loey (2009) Influence of pressure/temperature treatments on glucosinolate conversion. Food Chemistry 112:646-653.

Wagner H., S. Bladt and V. Rickl (2009) Plant Drug Analysis: A Thin Layer Chromatography Atlas. Springer, USA. 384 p.

Wittstock U. and B. A. Halkier (2002) Glucosinolate research in the Arabidopsis era. Trends in Plant Science 6:263-270.

Yonas K. and A. Amare (2008) Postharvest biological control of anthracnose (Colletotrichum gloeosporioides). Postharvest Biology and Technology 50:8-11. 